\title{
A CHECK-LIST OF TESTS FOR VARIOUS TYPES OF PROFICIENCY IN A FOREIGN LANGUAGE*
}

\author{
Joseph K. Yamagiwa \\ University of Michigan
}

World War II has already receded a dozen years into the past, andiit may seem like a piece of gratuitous archaeologizing to dredge out of some ancient files a report sent to the proper authorities of the Army on the procedures followed in the Army Japanese Language School at the University of Michigan, in which large numbers of soldier trainees "took" varying amounts of "intensive" Japanese. However, the procedures adopted in teaching this service personnel have proved extremely useful in these postwar years; as an example, the oral approach to the teaching of spoken Japanese, tried and refined during the war years, has given new life to civilian teaching.

The service personnel attending the Army Japanese Language School were on the whole students of high caliber with perhaps an average of two years of college training. Keenly competitive as far as ratings in their classes were concerned and highly. motivated in view of the critical nature of the intelligence work for which most of them were headed, they were generally "easy to teach" and "quick to learn." Necessarily, their standings in sections and groups depended not only on their daily work but on the battery of tests to which they were subjected. The report to which we have referred contains a listing of the types

\footnotetext{
*Editors' Note; The author, Professor of Japanese and Chairman of the Department of Far Eastern Languages and Literatures at the University of Michigan, here recalls the test-types given to service personnel in the University's Army Japanese Language School, of which he was director during World War III. His description of the spoken language program conducted in the Army Japanese Language School is found in Language Learning, 1.2 (April, 1948), 11-23. The author refers interested readers who might wish to pursue the entire matter of tests for various proficiencies in a foreign language to Professor Robert Lado's Annotated Bibliography for Teachers of Englishas a foreign Language. Washington, D. C. , the U.S. Office of Education, 1955.
} 
of test used in evaluating the trainees, together with comments on the general efficacy of these tests. Perhaps these testtypes need refinement. Perhaps, for the particular purposes for which they were administered, some may be better than others. But when many series of tests had to be given and a variety of tests was required in order to add to the freshness of testing procedure, a degree of ingenuity became essential. The following description of the testing program in the Army Japanese Language School is thus written with a real sense of gratitude for the preparation of tests of various kinds and the administering of these tests done by the 105 members of the teaching staff who in the course of three years taught some 1600 officers and men of the United States Army and Navy.

\section{The system of examinations: introduction}

The examinations were given to determine the total proficiency of any student at any time in the spoken or written language, his relative standing in his class, and his week-by-week performance. Upon entering the Army Japanese Language School, the students of each class were given a placement examination. The results of this examination, combined with a consideration of each student's previous training in Japanese, helped to determine which section a student was placed in. Thereafter, weekly examinations were given on his work, with one of the two hours scheduled each Saturday morning devoted to a test on his written language work for the week, and the second hour devoted to an examination either on his spoken language work or on his work in the reading materials. The marks earned in the weekly examinations often resulted in a change in section assignments. Thrice a year, comprehensive examinations taking up a total of two consecutive days, and therefore eight hours, were given, and in many cases resulted in promotions and demotions to other sections and to other groups, each group consisting of two or more sections following the same program. Spot examinations, usually in the nature of a composition or of a piece of translation assigned to all the members of a class, or to several groups together, as a basis for the comparison of groups, were also given. Since the daily dictation work likewise was conducted in an atmosphere of high tension, the impression given, that there was a great deal of testing, is completely correct. Despite the possibility that certain students became grade-conscious under such a system, the highly competitive spirit created by the constant testing was very much like that of an Officer Candidate School. The weekly grades determined whether or not a student went to the Supervised Study periods. Since there was a tendency to regard these periods as 
a curtailment of liberty, at least of the liberty of studying in one's own room in comfort, the grading became very important to most students.

2. What total proficiency in the Japanese spoken language meant.

Ideally stated, the kind of control of the spoken Japanese language which the School wished to develop in its students was that of native speakers who possessed the same intelligence and education. The ideal naturally was bilingualism in English and Japanese. In a memorandum addressed to the teachers and students of the School, the following ideals were stated as goals toward which the spoken language work was directed:

a. Closeness to the norms of native pronunciation; the individual sounds, the accentuation, and the intonation would in good speech duplicate a native's control of the same.

b. Correctness (accuracy) in the use of vocabulary, phrases, and grammar forms, in the sense that a native's usage is duplicated.

c. Fluency as shown by quickness in comprehension, readiness in expression and response, the ability to sustain conversation to the fullest limits required in any language situation.

Naturally, these ideals can be achieved only after a long period of study and experience; at any single moment the proficiency shown by any student must be measured in terms of the materials that he has covered and the total experience that he has had with the language that he is studying within the limits of the materials and training, his proficiency may still be graded; the School, therefore, announced the following definitions of the grades that were given for the spoken language work:

a. A - Excellent

(1) Responses quick.

(2) Pronunciation and use of vocabulary, phrases, and grammar approximate native norms or through several sentences may even be mistaken for a native's.

(3) Speech fluent and sustained with no hesitation within the usual phrase limits; speech characterized by wide range of vocabulary, idioms, and grammar, and deft use of the same.

b. B - Good

(1) Responses quick.

(2) Pronunciation, vocabulary, phrases, and grammar deviate from native norms. 
(3) Speech comparatively fluent but marked by occasional hesitations, due at least in part to not knowing or not controlling a wide range of vocabulary and phrases; limits evident in the deft and varied use of vocabulary, phrases, and grammar forms.

c. C - Fair

(1) Responses not quick, and in rare instances may be wrong.

(2) Pronunciation, vocabulary, phrases, and grammar deviate quite markedly from native norms.

(3) Speech generally understandable but halting; range of vocabulary, phrases, and grammar narrow.

d. D - Poor

(1) Responses definitely slow, sometimes wrong.

(2) Pronunciation and use of vocabulary, phrases, and grammar definitely poor.

(3) Speech very hesitant and often not understandable; sustained, intelligible conversation not possible.

3. E - Failure

(1) Responses and expression too faulty to be intelligible.

(2) Pronunciation and use of vocabulary, phrases, and grammar show almost complete lack of control.

(3) Speech very much confined to ordinary greetings and elementary phrases; sustained conversation not possible.

Plusses were added to the above grades for superior performance, minuses were added for inferior performance.

3. What to test for in the spoken language.

In attempting to arrive at a judgment and evaluation of any student's control of spoken Japanese, the attention may be focused on the following elements of his speech:

a. His ability to talk; the ability he shows to sustain a conversation to its ultimate length, initiating it with questions or statements, responding as needs be; his fluency.

b. The degree of his ability to comprehend what others say.

c. His pronunciation.

d. His control of vocabulary.

e. His control of grammar forms.

Teachers soon find, and an analysis of the tests conducted in the School show, that in trying to test for oral fluency, the other 
factors mentioned invariably come in. Most tests examine a student's proficiency in more than one phase of linguistic competence, and more than one aspect of language proficiency is usually tested at once, with a grade or rating given on the total impression. The intrusion of the subjective element, the giving of poor tests, or poor administration of good tests may all result in evaluations that do not accurately describe a student's competence. Hence, few tests can tell the full story of a student's proficiency; several tests are necessary. The following paragraphs will describe, however, the testing procedures used to measure each element of speech mentioned in the above list.

4. Tests on comprehension and the ability to express oneself in Japanese.

In testing the students of the Army Japanese Language School for comprehension and the ability to talk, the teacher often took an active part, since it was he who usually began by directing in Japanese the oral responses which the students were to make, and it was he who asked the questions that the students were to answer. The students listened and responded, as directed, in these examinations. In his grading the teacher considered promptness in answering, correctness in the use of vocabulary and grammar items, the choice of words, pronunciation, and completeness in the answers. The students in these examinations listened to the teacher's directions and questions and responded as requested.

a. The teacher specified vocabulary items and phrases, and had the students make sentences with them. The answer was sometimes in the nature of an explanation, as of a process or procedure.

b. The teacher specified both the vocabulary and the grammar forms that were to be used and had the students make sentences with them.

c. The teacher specified a vocabulary item, and had the student give its opposite.

d. The teacher specified a vocabulary item, with or without a specified grammar form, and had the student make a question containing it, which a second student had to answer.

e. The teacher had two or more students converse with each other on a given topic.

f. The teacher had the students discriminate between two things that are similar, such as given names and surnames.

g. The teacher had the students describe what something was, what was in a picture, what was in a magazine, etc.

h. The teacher had the students give reasons why some action was difficult. 
i. The teacher started a statement and had a student complete it orally.

j. The teacher asked a question and had the student answer it as fully as possible. The questions could be so phrased as to demand specific answers arising out of the materials used in the lessons learned during the preceding week or month. Thus the teacher could ask, "Isn't Mexican cooking on the sweet side?" and the student might be expected to answer, "No, it is on the hot (peppery) side."

k. The teacher asked sentences in sequence, that is, with an initial question followed up by others. Complete answers were asked for; the student carried on a conversation with the teacher. The questions

(1) could illustrate the grammar forms learned during the preceding week. The phrasing of the question could be such that the students would have to answer in various styles, that is, using honorific or humble forms, abrupt forms, polite forms, or the forms of informal speech.

(2) could cover the materials taken up during the immediately preceding "Speech Hours," including dialogues, compositions, and movie reviews. The contents of the materials used during the Speech Hours had to be well known if the answers were to be given high grades.

1. The teacher started with a series of questions that were grouped in terms of difficulty in answering. Usually four groups were used, the easiest questions marked $D$, the next harder marked $C$, the next $B$, and the hardest $A$. The students answered the questions asked of them, and received as their grade the rating of the most difficult question or questions that they were able to answer. Very competent answering resulted in a plus being added to the letter grade, and imperfect answering resulted in a minus.

The examination types designated $a, b, c$, and $d$ above tested especially a student's knowledge of isolated vocabulary and grammar items. The other types seemed preferable in that they simulated more closely the actual conditions of speech, and told the teacher something of a student's ability to initiate and to sustain conversation to its fullest limits. They tested more than the ability to comprehend. Examination-type $i$ calledfor complete alertness on the part of the student, especially if quickness in response was being measured. Examination-type $l$ bears fruther description, since it is the closest that the School came to objective testing of speech ability. 
5. The "ABCD exam"

Examination-type $l$ has come to be known as the "ABCD exam." As stated, a full description seems justified because it is the closest that the School came to devising an examination that tested proficiency in speech. The corps of examiners began by grading each question in terms of its difficulty. The easiest to answer were marked $D$, the next harder were marked $C$, etc. The students usually were given two or more questions of each grade. Proper answering of a question marked D or of two questions marked $D$ meant that a student had earned at least a D grade, and qualified him for an opportunity to answer $C$ questions. His grade for the examination was that of the highest grade of question that he could answer satisfactorily. A "plus" was added if his answering was done in superior fashion, and a "minus" was added if his answering was done in an inferior way.

In the classroom all students answered D questions first. If anyone faltered, he was usually given a second D question. A second failure usually meant an $\mathrm{E}$ for the examination grade, but successful answering of one or more $D$ questions meant that the student had earned at least a $D$ grade. When all of the students had answered their D questions satisfactorily or unsatisfactorily, the teacher proceeded to the $\mathrm{C}$ questions, asking them of the students who had answered the D questions satisfactorily. If any student failed on two or three tries at a $C$ question, his grade remained a $D$, but during the rest of the examination the teacher returned to him with $\mathrm{D}$ or $\mathrm{C}$ questions, so that he would not consider himself left out of the proceedings. For the same reason, those students who had failed on the $D$ questions were given the opportunity of answering additional $\mathrm{D}$ questions.

The "ABCD exam" fails unless the questions are carefully evaluated. In the Army Japanese Language School, only those teachers who were known to be strict in their grading and able to maintain a fairly consistent scale of judgment were asked to administer, the examination. Thus, the number of students in the sections "being examined became larger and more time had to be taken. To illustrate the workings of an "ABCD exam" at the very beginning of a course, the examination given on June 2, 1944 to a group of students when they first arrived at the school may be described. In this examination two very elementary "E" questions were included, each student being asked his name and the name of an object in the room. The assumption was that students coming with any previous training in Japanese, even for a few days, would be able to answer these questions, since statements 
of the type "I am John Smith," "This is a chair," and "That is a window" are just as simple in Japanese as in English, at least in the sense that they are among the first learned. If these questions could not be answered, it was assumed that the students should begin their course from scratch. The " $\mathrm{D}$ " questions were also of the form "What is this?" "What is that?" with the instructor pointing out various objects in the room. These objects might include an eraser, the blackboard, the electric light, a watch, a match, a magazine, a dictionary, coins, etc. If the identifications were correctly made in Japanese, then a follow-up question, asking for data concerning the uses of the object identified, was directed at the student. Thus, if the student knew how to say eraser in Japanese, he was asked, "What do you use it for?" If he knew the word for electriclight, the next question was, "When do you turn it on?" Grammatically speaking, the answers now called for the use of certain verbs in the present tense forms. In the case of " $\mathrm{C}$ " questions, each student was asked for various simple data relating to his past experiences, of the type:

Where did you come from?

Where did you study Japanese?

Why did you study it?

Have you studied other foreign languages?

What do you like to do?

Why?

What do you want to become?

Why?

Ease in answering these questions would show that a student had gained elementary control of Japanese, and could understand and respond to simple questions. The " $B$ " questions included the following:

Where is Japan?

Please tell us about Lincoln.

Please tell us about George Washington.

Please tell us about Franklin Roosevelt.

To get to Michigan from California, what places do you pass?

Explain some things concerning your home town.

The students were thus asked to describe the location of a geographical area, to give a description of a famous person, or 
to relate the details of a trip. They were obliged to show that they knew the vocabulary and grammar necessary for the description in Japanese of facts of a simple nature. The " $A$ " questions placed the instructor and student in a hypothetical situation, and the student was asked to question the instructor on various aspects of the situation. Thus the instructor said:

Last night the lady who roomed upstairs in my home was killed by someone. If you were a reporter, what questions would you ask me?

Or,

I am a student at the Navy Japanese Language School at Boulder. Ask me some questions about that school.

Or,

In a hotel in a certain town, the manager and a guest are talking. The guest wants to know various things concerning that town. If you were the guest, what would you ask?

The situations were such as to demand accurate understanding; otherwise, the questions asked by the student would not have been pertinent. The situations also were a measure of the student's intelligence; if the questions asked were neither many nor relevant, he showed that in Japanese at least his command of his faculties at any moment could not be completely trusted.

Easy and deft questioning, on the other hand, would convince the examiner that the student had gained considerable command of Japanese. The results were such that in one section the following grades were attained:
A
1 student
B plus
3 students
B
7 students
C
4 students
D

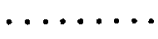
4 students
D minus
2 students
E plus
1 student 
By the end of any course, the questions of an "ABCD exam" became much more difficult. Thus, " $D$ " questions might ask for simple definitions, simple enumerations, and statements giving elementary facts. The teacher might ask:

Where are the South Sea Islands?

What does an army doctor do?

Name some epidemic diseases.

What do you mean by a piercing wound?

What does the pilot of an airplane do?

"C" questions might call for statements giving rather obvious reasons for procedures, or statements giving the dates and places of various events, or statements describing simple actions:

Where did Wilson (a character in a dialogue read by the students) receive his basic training and for how long?

What did they do with empty ammunition cases in the last war?

Why don't you have very much training with live ammunition at an army training camp?

How does malaria spread?

"B" questions might call for statements giving comparisons, for statements giving enumerations of rather technical vocabulary, and for statements giving reasons:

What is the difference between training with live ammunition and with blank ammunition?

What are the most dangerous types of ammunition, that is, to the soldier who is being shot at?

How does it happen that a shell sometimes doesn't explode?

"A" questions might ask for statements giving reasons of a more or less elaborate nature or for statements describing relatively difficult procedures:

In what situations do you use camouflage netting?

What are the purposes of army training and are these purposes adequately accomplished in the American army? 
How are supplies and ammunition sent to the fighting front?

What would you bomb if you commanded a B-29 group? Why?

The "ABCD exam" might thus be made to fit the proficiency and previous training of the students; when given to the best students near the end of their training, the " $\mathrm{D}$ " questions might be omitted since the expectation would be that all of the students would answer them properly. It seemed advisable in all cases to ask follow-up questions, that is, to give questions in sequence, to test the thoroughness of any student's knowledge concerning any subject that had been opened up. If all of the students in any section taking an "ABCD exam" could be induced to make corrections on matters both of language and fact, and to add details, a sense of great alertness could be maintained and the grades adjusted in terms of each student's contributions.

6. Tests on the ability to speak.

The tests specified in section 4 involve an initial act of comprehension on the part of the students, since the examiner begins by stating a direction or question in Japanese. However, all of the examinations described in section 4 , and especially those of types $e, f, g, h, i, j, k$, and $l$, give clear indications of a student's capacity to speak Japanese. If a direction is given in English, the student is even more on his own in doing whatever he is asked; he is now forced to use his Japanese productively, without the benefit of even one question in Japanese. In the Army Japanese Language School the following test-types were used to examine each student's ability to speak:

a. The student was asked to translate sentences from English to Japanese. The English was written or spoken, and graded, like the questions in an "ABCD exam," in terms of difficulty. Since English was used, conversations in Japanese were not carried on between teacher and student, but it was possible to discover a student's control of relatively difficult constructions by this method.

b. The student was asked to talk extemporaneously on one or more given topics that were based on his experience and knowledge. The topics were chosen by lot from prepared slips on which they were written out. Aside from a student's language competence, this test told the examiner something of his general intelligence; the student's manner of delivery told the examiner 
the degree of his control over his ideas when speaking to a group.

c. The student was asked to make inquiries on a given situation, to see how much information he could discover. This is of the type of the " $A$ " questions in the placement examination described in section 5 .

In the foregoing tests the instructor made notes on any or all of the following elements of speech: pronunciation, wordorder, word-selection, control of grammar forms, fluency, and content.

7. Tests for comprehension.

Tests to discover the degree of a student's comprehension were relatively simple to design. They consisted of the following types:

a. The true-or-false examination.

b. The multiple-choice examination.

c. Asking a student to do whatever was asked or to act out a narrative.

d. Asking a student to translate materials that were written either in romanization or in characters.

A judicious mixture of easy and more difficult statements and questions usually resulted in a rather accurate appraisal of a student's ability to understand Japanese.

8. Tests for pronunciation.

Two types of examinations for pronunciation were used:

a. The reading of a passage, with the examiner making notes on such matters as

(1) The qualities given to the consonants and vowels, especially to the $r$ which is Japanese is of the flapped variety.

(2) Length of sounds: watching to see if long consonants and vowels were made short or short ones long.

(3) Pitch accents on specific words.

(4) Intonation of phrases and sentences.

b. Multiple-choice examination, administered orally or in writing, with the students marking the right answer from such pairs as agette and agete. This type of examination was also used to examine the student's control of particles, wordorder, inflected forms, and word-selection. In giving pairs, care had to be exercised to see that only one answer in any pair was the right one, and that the wrong ones were sometimes used by some of the students and hence were not completely absurd. 
9. Tests on vocabulary and diction.

a. The matching test: the student was given two sets of words, one in English, one in Japanese. The entries in English were numbered, the entries in Japanese had pairs of parentheses placed in front of them. The numbers belonging to the English words were placed in the parentheses that belonged to the appropriate Japanese words. This type of examination tested the range of a student's vocabulary.

b. The student was given a series of sentences in romanization or characters, with certain words left out. Sometimes the items asked for belonged to such categories as the particles, that is, to categories that perform grammatical functions in sentences.

nyms.

c. The students were asked to give synonyms or anto-

d. The students were asked to make a choice from multiple possibilities. The English equivalent could be given, with two or more possible Japanese equivalents; or vice-versa. Or, the student was asked to give honorific, humble, abrupt, polite, or informal equivalents.

It was possible to use the above tests in ascertaining knowledge of specialized vocabulary, such as that for geography and the military.

10. Tests on the knowledge of spoken grammar.

The various tests for control of grammar items could be specialized to examine a student's use of particles, sense of word-order, knowledge of inflected forms, and control of grammatical terminology.

a. The student was asked for such inflectional forms as those of the verbs and adjectives, and for such uninflected forms as the particles and numeral auxiliaries (equivalent to "head" in "three head of cattle"), in spaces that were left open in sentences written either in romanization or in characters.

b. The student was asked to fill in several forms for such inflected categories as the verbs and adjectives, in paradigmatic charts or grills provided for the purpose.

c. The student was asked for the translation of underlined passages in English or Japanese sentences.

d. The student was asked to compose sentences using designated forms.

e. The student was asked to make the right choice between' two or more possibilities indicated in writing, that is, to make 
a choice between two or more particles, between two or more inflected forms, or between two sentences that contained the same words in different order.

f. The student was given a series of sentences containing forms that were underlined and followed by parenthesized grammar terms that described or did not describe the underlined items.

g. The student was asked to give polite, abrupt, honorific, humble or informal equivalents.

In general examinations on grammar tested also the student's control of vocabulary and meaning.

11. Tests on the older literary forms found in the modern Japanese written language.

In tests searching into the knowledge of the older literary forms (bungo forms) found surviving in the modern Japanese written language, the students were asked

a. To restate, using bungo forms, sentences containing spoken language forms.

b. To restate sentences, phrases, or words expressed in bungo in their spoken language equivalents. The phrases and words were given as parts of complete sentences, and underlined (if in romanization) or sidelined (if in characters).

c. To translate Japanese sentences containing bungo forms into English. Sometimes the forms were underlined (if in romanization) or sidelined (if in characters), and translated by themselves.

d. To translate English sentences into Japanese, using bungo forms in the translations.

e. To compose sentences, using the bungo forms.

12. Tests on the reading materials.

The students covered enormous amounts of reading material, both in romanization and in the characters in which Japanese is written. When these materials were regarded as the basis for speech, the same types of examination used in testing for proficiency in the spoken language were used. Thus

a. The instructors had the students compose sentences using specified vocabulary items that were found in the texts.

b. The instructors had the students change certain sentences found in the texts into others containing honorific and humble forms, informal forms, etc.

c. The instructors had the students answer questions based on the text. 
d. The instructors had the students recall particular lessons learned during the preceding week, and give summaries, synopses, or paraphrases.

e. True-or-false tests were given on the contents of the lessons, with the statements given either orally or in romanization.

f. The instructors asked for translations into English of chosen passages in the text. If characters were used instead of romanization, the knowledge of these characters played a part in the students' ability to give acceptable translations. Translations into Japanese also afforded a check on the students' ability to construct acceptable Japanese sentences.

The foregoing procedures duplicated those used for the testing of spoken language proficiency. On the other hand, it was understood that especially in reading aloud it is the eyes that receive the first stimulus and the speech organs that make the final response; to achieve accurate, fluent, and well modulated reading, the characters on any page must be recognized at once and oralized as if the reader were talking in meaningful phrases. Hence, examinations that tested a student's reading ability had to be developed:

a. The instructors had the students read designated lines or pages. The grading took into account the accuracy, fluency, and pronunciation. The reading was followed by

(1) asking the students to paraphrase the passages that they had read, that is, to express them in simpler Japanese.

(2) asking the students questions on the passages read.

b. The instructors gave a true-or-false examination, in which the statements were written in characters, and squares provided above them in which to mark $\mathbf{T}$ or $\mathbf{F}$.

13. Examinations on the kanji or Chinese characters used in writing Japanese.

These may be listed as follows:

a. Dictation of sentences covering the $k$ an $j i$ learned or reviewed during the week. The students were asked to listen to three readings of the sentences, first for comprehension, secondly phrase by phrase for writing, and thirdly for checking. The sentences were written in $k a n j i$ and kana, the latter being the syllabic characters used in writing Japanese and consisting of two types, the more angular katakana and the more cursive hiragana. Words borrowed from foreign languages were put in katakana, as is customary. The dictation type of examination 
tested not only the students' knowledge of characters, but their ability to comprehend, their knowledge of vocabulary, and their knowledge of kanazukai, that is, of spellings in the syllabic characters. The characters that the students wrote were also sometimes graded as to neatness.

b. Romanized sentences were given, with rewritings into $k a n j i$ and kana asked for.

c. Romanized phrases were given, with some of the words underlined; the underlined words were given by the students in characters, sometimes with meanings. Giving phrases instead of single words clarified the context in that the choice among homonyms became delimited.

d. (1) the kanji or compound of two or more kanji was given, the pronunciation and meaning asked for.

(2) The pronunciation was given, the kanji or compound and meaning asked for.

(3) The meaning was given, the kan $j i$ or compound and pronunciation asked for.

Sometimes two of the three kanji or compound, pronunciation, meaning) were given and the other asked for. Katakana writings for words borrowed from foreign languages were sometimes included.

e. (1) Sentences were given in characters with some of the words expressed in kana or romanization; kanjiwere asked for the words in kana or romanization.

(2) Sentences were given in kana (katakana or hiragana) with spaces or squares left underneath certain words for inserting kanji.

f. Inflected words made up of a stem and endings were given in romanization; kanji and okurigana, the latter used to express the endings, were asked for. Since the okurigana sometimes had historical, non-phonetic spellings, this examination served partly as a test of the students' knowledge of such spellings.

g. English sentences were given, with the students asked to write their translation into Japanese in characters, using $k a n j i$ and katakana or kanj $i$ and hiragana, as designated.

14. Tests on the students "knowledge of historical kanazukai (spellings in kana).

Some of the examinations listed in the foregoing section helped to test the students' knowledge of historical and nonphonetic spellings in kana. Examinations of the type $a, b, f_{,}$, and $g$ fall into this category. Other tests of a student's knowledge of historical spellings in kana included: 
a. The historical kana spellings were given, and proper romanizations asked for.

b. Romanized sentences were given, with certain portions underlined; these underlined passages were given by the students in historical kana spellings.

15. Compositions and translations as tests.

From time to time, especially when placement, comprehensive, and spot examinations were given, the students were asked to write compositions. If the writers came without special preparation, and if dictionaries and grammars were not used, the compositions reflected

a. Control of vocabulary.

b. Control of grammar forms.

c. Knowledge of characters and of spellings in kana if written in characters.

d. General ability to express oneself, especially if written as the students spoke, without attempting to be over-literary.

e. General intelligence, originality and ingenuity, sense of unity, coherence.

In asking students to write compositions, the choice of topics was all-important if all of the students of any class were to be tested together. The subjects chosen had to be broad enough to fall within the experience of each student. Typical subjects were the following:

a. The University of Michigan.

b. Japanese movies.

c. The study of the Japanese language.

If any class or group of students were composed of beginners or near-beginners, the compositions could be written in romanization; in the case of advanced students; the compositions were usually written in $k a n j i$ and kana.

Translations, especially translations from English into Japanese, were like the compositions in what they tested. The originals, however, were fixed, and in translation there was no great play of a student's general intelligence, of his originality and ingenuity, or of his sense of unity and coherence.

16. Tests on knowledge of factual data.

As the students progressed in their work and gained proficiency both in the spoken and written languages, they were able to take up materials that possessed greater and greater content 
value. Among these materials were a geography text, a set of military dialogues and $\bar{a}$ Heigo or military reader, the topographical sheets prepared by the Japanese Land Survey Department, and dialogues that had to do with military government. The tests taken on these materials showed the degree of control possessed by the students over technical terms, such as those relating to geography, the military, communications, surveying, and civil administration. Moreover, when the students were asked to write short essays covering these subjects, a great deal was learned of their general intelligence. When the various materials named were regarded as the basis for conversation, the testing procedures were the same as those employed for the spoken language. Thus,

a. Questions pertaining to the texts used during any week were asked. If the materials were military, the students could be asked

warfare,

(1) what the ranks of the Japanese army were,

(2) why the topography of China is suited to guerilla

(3) what the nature of the fighting on Palau was.

Or, if the topographical sheets were being covered, the instructor could ask questions pertaining to the scales used in the sheets, the surveyor, the dates of publication, and the publisher. On any sheet the students could be asked to give explanations concerning

(1) the location, number, and types of barracks, schools, government offices, and factories,

(2) the geographical and man-made features that surrounded a given point, particular area,

(3) the highways, railroads, etc. that traversed a

(4) what was to be seen on both sides of a road,

(5) what was grown in the neighboring fields. lary items.

b. The students were asked to explain various vocabutopics.

c. The students were asked to give short talks on various

The Heigo or military reader and part of the geographical materials were written in characters. Here the students could be given the same types of examination as for the other reading materials:

a. They were asked to read specified passages, and were graded on the basis of accuracy and fluency. 
b. They were asked to fill in incomplete statements based on the texts.

c. They took true-or-false tests on the materials covered, appropriately marking statements that were written in $k a n j i$ and kana.

d. They were asked to write short essays on questions that were written in characters.

The Heigo or military reader, when used, was made the source of the characters which the students had to learn for the dictation hours. Here again asked for.

a. Sentences were dictated.

b. Kanji were given, and pronunciations and meanings

c. Meanings were given, and pronunciations and characters asked for.

The various materials here considered afforded an opportunity for special testing devices. In testing for knowledge of geographical data

a. The examiner issued

(1) a map with letters and numbers on it, designating various features,

(2) a separate sheet containing romanizedplace-names.

The students were asked to give on the second sheet, next to the place-names, the appropriate letters and numbers shown on the map.

b. The examiner issued

(1) a map with letters and numbers on it, designating various features,

(2) a separate sheet giving the letters and numbers again.

The students were asked to give on the second sheet, in romanization or characters, the names for the features that corresponded with the letters and numbers.

c. Making use of a wall-map, the students were asked to point out place-names.

The topographical sheets were like the maps. They were, however, peculiar in that special symbols designating such features as temples, shrines, schools, government offices, barracks, naval yards, etc. were liberally shown on them. To make sure that the students knew completely the significance of these symbols 
a. the symbols were drawn on the blackboard or shown on flash-cards, and the students asked to identify the symbols seen. In identifying any symbol, the Japanese name for the thing symbolized was given orally, or the characters for that name were written down on paper.

b. the examiners provided

(1) a map containing the symbols, with the symbols variously numbered,

(2) a sheet giving in kanji the names of the objects which the symbols designated,

and the students were asked to give on the second sheet, next to the appropriate kanji, the same numbers as those given to the symbols on the map.

17. The combining of test-types in various examinations. The foregoing test-types were combined in various ways in the weekly, placement, comprehensive, and spot examinations. A typical weekly examination given on Saturday, September 8, 1945, consisted of the following test-types:

a. On the reading materials for the preceding week:

nunciation

(1) Reading with accuracy, fluency, and proper pro-

(2) Explaining in Japanese the meaning of important words and phrases in the passages read

(3) Translating English sentences into Japanese orally and phrases

(4) Composing sentences, using specific Japanese words

b. On the characters:

Dictation of 39 sentences covering the kanji and grammar forms learned during the week.

On the following Saturday, September 15,1945 , the examination on the reading was replaced by one on the oral work. Here the students were asked ing the week

(1) To answer questions on the materials covered duritems

(2) To compose sentences using specific vocabulary

(3) To converse, two at a time, on a specified topic.

The placement examinations given to an incoming class in late May and early June, 1945, consisted of the following tests:

a. In the spoken language:

(1) 50 true-or-false statements; - to test the incoming students' ability to comprehend oral statements. 
(2) Given 400 Japanese words, to give the right English words out of several choices; - to test range of vocabulary.

(3) Given 100 Japanese words or phrases underlined in complete romanized sentences, to give translations for the words and phrases; - to test range of vocabulary and grammar.

(4) Given 100 English words or phrases underlined in complete sentences, to give translations for the words and phrases; - to test range of vocabulary and grammar.

(5) ABCD questions as described in section 5 above; to test comprehension, pronunciation, fluency, ability to sustain a conversation, general intelligence as revealed by thoughtfulness in the answering.

b. For the written language:

(1) The writing of a composition; - to test the ability to express oneself in writing; this also tested range and precision in use of vocabulary and of grammar items and general intelligence as shown by the sense of unity and coherence developed in the compositions.

(2) Test on knowledge of kanj $i$ :

(a) $150 k a n j i$ given; pronunciations in romanization and meanings in English called for.

(b) 150 pronunciations given; $k$ anji and meanings asked for.

(c) 150 English words given; $k a n j i$ and romanized pronunciations asked for.

Comprehensive examinations' usually covered two successive days. The one given to an advanced group of students in July 1945 consisted of the following tests:

a. On the spoken language work:

(1) Questions in sequence.

(2) Given a map with place-names numbered and lettered on it, to give on a second sheet the place-names designated by the numbers and letters; - 33 entries in all.

(3) Given 21 incomplete geographical statements, to fill in various entries.

(4) A matching test, in which 30 Japanese words were matched against 35 English words. The numbers given to the English words were given by the students to the appropriate Japanese words.

(5) A multiple-choice test, with 20 Japanese words given, each with three possible meanings. The right meanings were underlined by the students.

b. On the reading materials:

(1) Translation into English of 15 Japanese sentences taken from the texts studied in the immediately preceding month. 
(2) Translation into Japanese of 15 English sentences.

(3) Reading of specified passages, with grading based on pronunciation and fluency.

(4) True-or-false statements, written in characters, appropriately marked.

c. On the written language:

(1) Dictation of 30 sentences.

(2) Given $50 k a n j i$ and compounds, to give pronunciations and meanings.

(3) Given 50 pronunciations, to give $k a n j i$ and meanings.

(4) Given 50 English words, to give kanji and pronunci-

ations.

(5) A composition, "On the study of the Japanese language."

Finally, a spot examination given on July 27, 1945 to all of the students in the School was made up of the following:

a. Translation of designated passages in the reading materials. The same passages were given to all of the students, regardless of standing in sections or groups, in order to arrive at a comparison of proficiencies.

b. The writing of a composition on Japanese movies.

18. Grading.

In so large a school as the Army Japanese Language School, it was extremely difficult to keep the grading of the students uniform. This was especially true in the grading of spoken language proficiency. Some teachers were by nature strict, and adhered to the definitions of the grades $A, B, C, D$, and $\mathbf{E}$ given in section 1 above. On the other hand, at least one instructor was known to score students on the basis of 100 and to give a whole section of average students grades alternating between 98 and 100. When the grading was especially crucial, as in the case of the comprehensive examinations, the students were promoted or demoted from section to section or even from group to group on the basis of their scores. In these examinations, only a small number of instructors could be asked to administer the tests. Those tests, usually of the $A B C D$ variety described in section 5 above, were the closest that the School came to devising an objective spoken language examination. It was also found useful to give to each group of instructors a scale of expectations which would tell at any given time in a course, for any group of students, approximately how many $A^{\prime} s, B^{\prime} s, C^{\prime} s$, etc. there should be. This scale of expectations was based primarily 
on close examination of the students' proficiency and progress and on prior experience gained in the teaching program. The combination of strict instructors, definition of grades, tests thought to be the most objective possible, and a scale of expected grades gave some assurance of objective grading. On the other hand, a subjective element undoubtedly crept in, and a final comparison of grades given by the various instructors who administered the tests led sometimes to a raising or lowering, by a plus or minus, of the grades given by any particular instructor. In the case of the reading materials, that is, of materials written in $k a n j i$ and $k a n a$, the point of view, as expressed before, was that they were just as much a basis for spoken language drill as the materials written in romanization. The reading test, in which the students reacted orally to characters printed on a page, introduced a somewhat new element. Accuracy in reading the characters was probably more difficult to achieve than accuracy in reading romanization. The degree of accuracy was, of course, a factor in the grade given to work in the reading materials. On the other hand, the tests given on the reading materials were often of the same sort as those given for the spoken language materials, and the same scale of grading applied to the latter was equally applicable to the former. The correlation shown in the weekly grades was very close.

The procedures followed in giving dictation has already been described. Briefly stated, three readings were given, once for comprehension, once phrase by phrase for writing, and once again completely for checking. The speed was controlled by the instructor who watched the progress made by the majority of the students as he dictated. No questioning was allowed. The papers, turned in at the end of the dictation period, were corrected on that day, and corrected meticulously, with the instructors initialing the papers that they had corrected. In the case of the comprehensive examinations, the sentences written by the students were divided among several instructors, one instructor correcting the first five sentences, a second instructor correcting the next five sentences, etc. If the instructors differed in meticulousness of grading, any deviation from strict correcting was thus confined to a few sentences and spread evenly among the students who were being tested. The rules governing the counting of errors were rigidly stated. The errors made from day to day were recorded in registers and at the end of the week compared against the following scale: 


\begin{tabular}{|c|c|c|c|}
\hline \multicolumn{3}{|c|}{ Errors per day } & \multirow{2}{*}{$\begin{array}{l}\text { Grade } \\
\text { A plus }\end{array}$} \\
\hline 0 & -0.4 & $\ldots \ldots \ldots \ldots$ & \\
\hline 0.5 & -1.4 & $\ldots \ldots \ldots \ldots$ & $\mathbf{A}$ \\
\hline 1.5 & -3.4 & $\ldots \ldots \ldots \ldots$ & A minus \\
\hline 3.5 & -5.4 & $\ldots \ldots \ldots \ldots$ & B plus \\
\hline 5.5 & -7.4 & $\ldots \ldots \ldots \ldots$ & $\mathbf{B}$ \\
\hline 7.5 & -9.4 & $\ldots \ldots \ldots \ldots$ & B minus \\
\hline 9.5 & -11.4 & $\ldots \ldots \ldots \ldots$ & C plus \\
\hline 11.5 & -15.4 & $\ldots \ldots \ldots \ldots$ & $\mathrm{C}$ \\
\hline 15.5 & -20.4 & $\ldots \ldots \ldots \ldots$ & $\mathrm{C}$ minus \\
\hline 20.5 & -23.4 & $\ldots \ldots \ldots \ldots$ & D plus \\
\hline 23.5 & -26.4 & $\ldots \ldots \ldots$ & $\mathbf{D}$ \\
\hline 26.5 & -28.4 & $\ldots \ldots \ldots$ & $\mathrm{D}$ minus \\
\hline 28.5 & - above & $\ldots \ldots \ldots \ldots \ldots$ & $\mathbf{E}$ \\
\hline
\end{tabular}

In giving the final grades for any week, the daily average score was weighted at $50 \%$ and the examination score at $50 \%$. The grading depended partly on the difficulty of the tests. Here again a scale was provided. Thus for certain groups of students who had already received 30 weeks of training, the following suggestions were made concerning the number of characters to be used in any single dictation period.

$\begin{array}{lccc}\begin{array}{l}\text { Section } \\ \text { numbers }\end{array} & \begin{array}{c}\text { Number of Characters } \\ \text { in One }\end{array} & \begin{array}{c}\text { Number of } \\ \text { Kanji }\end{array} & \begin{array}{c}\text { Number of } \\ \text { Kana }\end{array} \\ 401-407 & 450 & 200 & 250 \\ 408-413 & 525 & 225 & 300 \\ 414-421 & 550 & 250 & 300 \\ 901-906 & 425 & 175 & 250 \\ 907-913 & 450 & 200 & 250 \\ 914-921 & 475 & 225 & 250\end{array}$

Certain adjustments were sometimes made. Thus, in any group, the lower sections were not always able to take dictation as fast as the upper sections. Any penalties against the lower sections 
were decided by the instructors in the group. Adjustments were also made in grading if a week's dictation sentences were adjudged to be exceptionally difficult or easy.

In the case of the placement and comprehensive examinations, a grading system had to be established for each of the several types of test, and the relative weight given to each test had to be carefully determined in arriving at a point total. The point scores were then translated into the grades of $\mathrm{A}, \mathrm{B}, \mathrm{C}, \mathrm{D}$, and E. Before the students were promoted or demoted as a result of the comprehensive examinations, the scores were compared against an up-and-down rating of the students prepared be fore the examinations were taken. This meant that the instructors' opinions were taken into account when the students were promoted or demoted; promotion or demotion did not depend solely on the scores made in examinations.

In certain cases the only possible basis for grading was the "bell curve" of scores made by all of the students. This was true in the case of true-or-false tests, multiple-choice tests, and the tests given on historical spellings in kana.

19. Special cautions in preparing and correcting examinations.

In preparing and conducting examinations, various cautions were followed:

a. The tests had of course to bear a definite relation to the materials that the students had covered; in taking the tests, the students recalled particular data in the materials or applied whatever they had learned.

b. The tests had to be varied enough, so that, if possible, more than one test-type was used in order to test each of the various types of competence.

c. The teachers giving the tests had to be carefully briefed, so that no inequities would arise out of the manner of conducting examinations.

d. To make the grading uniform and efficient, answer sheets and "overlays" for fill-in, multiple-choice, and true-orfalse statements had to be prepared.

e. The questions had to be stated clearly, so that no misinterpretations of meanings would arise. Complaints invariably arose if several answers "would do."

f. Special cautions, as on the proper marking of long vowels in romanized words, had to be given as necessary.

g. In correcting papers and in evaluating answers, the teachers had to suppress the influence of any subjective element that was due to contact with the students either in or outside the classroom. 
h. The spacing of such examinations as the comprehensives had to be very judicious.

The testing and grading of language competences is thus seen to be an extremely complicated affair. But in the course of a year it was possible to arrive at a rather accurate appraisal of each student's proficiency. The tests helped in arriving at these appraisals. 